\title{
Common Sports Injuries among Male Cricket Players
} in Bangladesh

\author{
Ehsanur Rahman ${ }^{\star, 1}$, Mst. Fatema Akter ${ }^{2}$, Md. Obaidul Haque ${ }^{3}$, Mohammad \\ Habibur Rahman ${ }^{4}$
}

\author{
${ }^{1}$ Assistant Professor, Department of Physiotherapy, BHPI, CRP, Dhaka, Bangladesh. \\ ${ }^{2}$ Senior Lecturer, Department of Physiotherapy, BHPI, CRP, Dhaka, Bangladesh. \\ 3 Professor 6 Vice Principal, BHPI, CRP, Dhaka, Bangladesh. \\ ${ }^{4}$ LecturerE Coordinator, School of Science and Technology, Bangladesh Open University, Gazipur-1705.
}

D DOI: https://doi.org/10.15520/jcmro.v2i11.229

Accepted 05-11-2019; Received 02-10-2019; Publish Online 08-11-2019
Reviewed By:
Dr. Ogolodom
Promise Department: Reviewer/CMRO

\begin{abstract}
Purpose: To evaluate the common sports injuries among male cricket player. Objective: To identify the prevalence of sports injuries among the male player, to expose the injured participants age, training duration and to identify the common site and type of injury and treatment taken after injury.

Methodology: A quantitative cross-sectional study design was chosen to achieve the objectives of the study. 100 subjects were selected through convenience sampling technique from the injured male cricket player who trained in Bangladesh Krira Shikkha Protishtan (BKSP)\& Bangladesh Cricket Board (BCB) by using a structural questionnaire to collect data.

Results: The result of the study demonstrates that, the peak age group was $\mathrm{n}=45$ $(45 \%)$ were between $18-20$ years. The bowlers $n=60(60 \%)$ are mostly affected by the injuries in cricket. According to the regional area shoulder injuries of the pain was $\mathrm{n}=40,(40 \%)$ in all shoulder injury $\mathrm{n}=25(25 \%)$ had rotator cuff injury from the total participants. From the total player $n=20(20 \%)$ Hand and finger injury most common was MCP injury $16 \%$. Out of thigh and hip injury among the 100 cricketers only $n=30(30 \%)$ had groin pain. From the total $n=20(20 \%)$ had knee and leg pain, out of 100 cricketers. The most common $n=71(71 \%)$ had indirect injury/ overuse injury. This study presents among severity of injury had $n=45(45.2 \%)$ had moderate injury. Among the participant $98 \%(n=98)$ were regularly attend in warm up and cool down activity and the duration of warm up and cool down $54 \%(\mathrm{n}=54)$ more than or equal 16 min. Heart rate was $70 \%(n=70)$ less than or equal 72 . The finding a lso reflects that the treatment was consisting physiotherapy as frequent as drug ( $48 \% \mathrm{n}=48$ taken physiotherapy, $16 \% ; \mathrm{n}=16$ taken drug and $36 \%$; $=36$ taken both).

Conclusion: The vulnerable age range 21-23 was frequent injury occurring among cricket player and noticeably flexibility and overuse are the key issues to cause of injury. Health education and perform regular physical activity along with physio therapeutic exercises can prevent injury.
\end{abstract}

Key words: Sports Injury-Male Cricket Players-BKSP-BCB.

\section{INTRODUCTION:}

Sports injuries have been reported with increasing frequency in a quest to identify patterns by which they can be predicted and prevented. Injury surveillance in cricket has been

\footnotetext{
* Corresponding author.
}

Email: ehsanurrahman09@gmail.com undertaken for almost a decade. The only sport with a true "World League" comprising 10 countries has not, however had universal reporting of injuries. Only reports from Australia, South Africa have been published, although other nations have started to setup injury databases and some for example England have produced reports [1]. In Bangladesh there is no such study about cricket injury. But there some 
study related to general sport injury. At those studies there is some information of cricket injury. They are mentioned below: According to Ashrafuzzaman [2], 15\% of the total injury at knee and ankle injury is more in cricket, football, basketball and hockey as compared to the other sport discipline. A survey to find out the injuries caused by participation in sports among BKSP students. At the study they recorded391 cases in ten different sports. From the result they concluded that among the ten different sports, percentage of injury is more at cricket, football and hockey. Among the injuries groin strain, neck pain, shin splint, Osgoodschllater's disease, patello-femoral joint disorder was more common [2].

\section{METHODOLOGY:}

The study conducted a quantitative method of crosssectional research design. Ten structured questionnaires were used for this study and samples were the injured Cricketers of BKSP and BCB who had injuries in between last one year of cricket playing. Samples were selected by convenience sampling procedure, because the cricket players remain in various tournaments on national and international level throughout the year. One to one interview was carried out by the data collectors through face to face interview in above mentioned study place. VAS scale, likert scale and English questionnaire was used to explore common sports injuries among male cricket players. After collecting data, these were entered into SPSS 16 software package. Descriptive statistics was used to analyze data and outcome was displayed as charts and graphs. This study was approved by the ethical committee of Bangladesh Health Professions Institute (BHPI), academic institute of Centre for the rehabilitation of the paralysed (CRP). The study was conducted from August 2017 to July 2018.

\section{RESULTS:}

\section{Age of the subjects:}

The mean age of the subjects was 19 years. However, among the 100 subjects $\mathrm{n}=29(29.0 \%)$ subjects were between $15-17$ years, $\mathrm{n}=45$ (45\%) were between $18-20$ years, $\mathrm{n}=23(23 \%)$ were between years $21-23$ years and $\mathrm{n}=3(3 \%)$ were greater than 23 years. Minimum age range was 15 years and maximum age range was 24 years.

\section{Specialty of the cricketers:}

The result showed that bowlers are mostly affected by the injuries in cricket. Among the 100 cricketers $n=60(60 \%)$ were bowler, $\mathrm{n}=30(30 \%)$ were batsman, $\mathrm{n}=08(8 \%)$ were all-rounder (both bowling and batting), $\mathrm{n}=2(2 \%)$ were wicketkeeper.

\section{Injuries of the cricketers:}

A. Regional injuries

B. Result showed that among the 100 cricketers $n=40$, (40\%) had shoulder injuries, $n=12,(12 \%)$ had hand and finger injuries, $n=22,(22 \%)$ had thigh and hip injuries, $n=11$,
(11\%) had knee and leg injuries, $\mathrm{n}=7(7 \%)$ had ankle injuries, $n=2,(2 \%)$ had foot injuries, $n=4(4 \%)$ had spine, back and trunk injuries and $n=2,(2 \%)$ had head and neck injuries.

\section{Shoulder injury:}

Among the 100 cricketers $n=40(40 \%)$ had shoulder pain, $\mathrm{n}=25(25 \%)$ had rotator cuff injury and $\mathrm{n}=15(15 \%)$ had shoulder instability.

D $12 \%$ had Hand and finger injury: Analysis showed that only $n=9(9 \%)$ had MCP injury and $n=3(3 \%)$ had mallet finger out of 100 cricketers.

E $22 \%$ had Thigh and hip injury: Among the 100 cricketers only $\mathrm{n}=7(7 \%)$ had groin pain, $\mathrm{n}=10(10 \%)$ had hamstring strain and $n=5(5 \%)$ had quadriceps contusion.

F $11 \%$ of total Knee and leg injury: Analysis showed that only $\mathrm{n}=5(5 \%)$ had collateral ligament injury and $\mathrm{n}=6$ $(6 \%)$ had knee pain out of 31 cricketers.

G $7 \%$ of total Ankle injury: Only $\mathrm{n}=4(4 \%)$ had ankle sprain and $n=3(3 \%)$ had ankle pain out of 100 cricketers.

H $2 \%$ Foot injury: Among the 100 cricketers only $\mathrm{n}=1(1 \%)$ had heel pain and $\mathrm{n}=1(1 \%)$ had great toe injury.

I $4 \%$ Spine, back and trunk injury: Analysis showed that only $n=4(4 \%)$ had back pain out of 100 cricketers.

J 2\% Head and neck injury: Analysis showed that only $\mathrm{n}=1(1 \%)$ had head injury and $\mathrm{n}=1,1 \%$ out of 100 cricketers.

\section{Types of injury:}

Analysis showed that $\mathrm{n}=29(29 \%)$ had direct injury and $\mathrm{n}=71(71 \%)$ had indirect injury/ overuse injury out of 100 cricketers.

Severity of injury:

Analysis showed that $\mathrm{n}=16(16.10 \%)$ had mild injury, $\mathrm{n}=45(45.2 \%)$ had moderate injury and $\mathrm{n}=38(38.7 \%)$ had severe injury out of 100 cricketers.

\section{Exercise:}

Among the participant 98\% ( $\mathrm{n}=98)$ were regularly attend in warm up and cool down activity and the duration of warm up and cool down 54\% $(\mathrm{n}=54)$ more than or equal $16 \mathrm{~min}$. Heart rate was $70 \%(n=70)$ less than or equal 72 .

Treatment:

The finding also reflects that the treatment was consisting physiotherapy as frequent as drug $(48 \% \mathrm{n}=48$ taken physiotherapy, $16 \%$; $\mathrm{n}=16$ taken drug and $36 \%$; $\mathrm{n}=36$ taken both). 


\section{DISCUSSION:}

Analysis showed $\mathrm{n}=60(60 \%)$ were bowler, $\mathrm{n}=30 \quad(30 \%)$ were batsman, $\mathrm{n}=08(8 \%)$ were all-rounder (both bowling and batting), $n=2(2 \%)$ were wicketkeeper. According to stretch [3] the incidences of the injury at bowlers were $47.4 \%$, which was greater than batsmen $(29.8 \%)$ and fielders $(22.8 \%)$. He also mentioned that, $66.6 \%$ injury was recurred. $29.8 \%$ of them from previous season and $36.8 \%$ of them were from same season. The incidence of sports injuries is $2 \%$ for wicket keepers [4]. According to Dannie [5] there is a constant relationship between high bowling workload and injury. So, it can be said that, bowlers get more injury and remain out of training and sports more. It may be for high workload than others. So, greater emphasize should provide towards bowlers to prevent their injuries. According to Finch [6] in high level of Cricket overuse injuries are most common due to physical demand of the sport and particularly while delivering the ball. On the other hand spinal overuse injury occurs more due to a mixed bowling action. Overuse injuries becoming more common because increased participation in general sports and increased intensity and duration of training. It was found that overuse injuries is more prevalent after 24 months of regular daily training [7].

According to Dannie [4] there is a constant relationship between high bowling workload and injury. So, it can be said that, bowlers get more injury and remain out of training and sports more. It may be for high workload than others. So, greater emphasize should provide towards bowlers to prevent their injuries. According to Finch [6] in high level of Cricket overuse injuries are most common due to physical demand of the sport and particularly while delivering the ball.

\section{CONCLUSION:}

It is important to develop research-based evidence of physiotherapy practice. Physiotherapist's practice which is evidence based in all aspect of health care. There are few studies on sports and sports injures in Bangladesh.

\section{REFERENCES}

[1] Mansingh A, Harper L, Headley S, King-Mowatt J, Mansingh G. Injuries in West Indies cricket. British journal of sports medicine. 2003;40(2):119-142.

[2] Cause of knee and ankle injury among BKSP student A survey. Journal of BKSP. 2002;4(2):108-117.

[3] Stretch RA, Venter DJ. Cricket injuries-a longitudinal study of the nature of injuries to South African cricketers. South African Journal of Sports Medicine. 2005;17(3):4-10.

[4] Orchard JW, James T, Portus MR. Injuries to elite male cricketers in Australia over a 10-year period. Journal of Science and Medicine in Sport. 2006;9(6):459-67.

[5] Dennis R, Farhart P, Clements M, Ledwidge H; 2004. Journal of science and medicine in sport.

[6] Finch CF, Elliott BC, Mcgrath AC; 1999.

[7] Peterson L, \&amp;renstrom. P Sports Injuries. 2001;. 